\title{
Histology and Physiology of Tissue Expansion
}

\author{
TIMOTHY M. JOHNSON, MD • LORI LOWE, MD \\ MARC D. BROWN, MD • MICHAEL J. SULLIVAN, MD \\ BRUCE R. NELSON, MD
}

BACKGROUND: Tissue expansion is a concept based on the skin's natural ability to stretch in response to an underlying force.

OBJECTIVE: The purpose of this article is to review the histological and physiological changes that occur within the soft tissue and underlying structures during tissue expansion. METHODS: An extensive search of the literature reviewing these changes is summarized herein.

RESULTS: Conventional tissue expansion may result in epidermal hypertrophy, decreased dermal, muscle, and adipose thickness, and bone resorption. A vascular capsule and angiogenesis provides a highly vascular flap and improves flap viability. Few soft tissue changes occur during rapid tissue expansion. The ability of the skin to increase in surface area during conventional tissue expansion is primarily because of biological tissue creep. Rapid expansion may result from mechanical tissue creep.

CONCLuSION: Many soft tissue changes occur during tissue expansion. Most of these changes return to the pre-expansion state over time following discontinuation of the expansion process. J Dermatol Surg Oncol 1993;19:10741078 .
1 issue expansion is an extraordinary concept based on the skin's natural ability to stretch in response to intrinsic and extrinsic forces. The natural ability of human tissue to increase in surface area as a result of these forces led Neuman to use an expander for ear reconstruction in $1957 .^{1}$ It was not until the 1970s that Radovan and Austad began to study the possibilities of slow, controlled expansion of the skin for reconstruction of the breast following mastectomy. ${ }^{2-4}$ The technique of conventional controlled tissue expansion has been advanced and refined to include virtually any area of the body. Hundreds of articles now exist describing the advantages of this unique procedure.

Immediate intraoperative tissue expansion is a modification of the conventional controlled tissue expansion technique that utilizes the skin's ability to immediately stretch and increase in surface area. Sasaki first reported this procedure in 1985 as intraoperative sustained limited expansion. ${ }^{5}$ Synonyms include: immediate intraoperative tissue expansion, ${ }^{6}$ immediate tissue expansion, ${ }^{7}$ rapid tissue expansion, ${ }^{8}$ intraoperative tissue expansion ${ }^{7,9}$ and rapid intraoperative tissue expansion. ${ }^{10}$

From the Departments of Dermatology, Otorhinolaryngology and Surgery (TMJ, BRN), University of Michigan, Ann Arbor, Michigan; Department of Dermatology, Chief of Dermatopathology (LL), Henry Ford Hospital, Detroit, Michigan; Department of Dermatology (MDB), University of Rochester, Rochester, New York; Department of Otolaryngology (MJS), Ohio State University, Columbus, Ohio."

Address correspondence and reprint requests to: Timothy $M$. Johnson, MD, University of Michigan, Department of Dermatology, 1910-0314 Taubman Center, Ann Arbor, MI 48109.
The actual techniques for tissue expansion are explained in subsequent articles within this journal. This review summarizes the histologic and physiologic changes known to occur with tissue expansion. For the purpose of clarity, these changes will be separately reviewed for conventional controlled tissue expansion and immediate intraoperative tissue expansion.

\section{Conventional Controlled Tissue Expansion}

Ultrastructural and Soft Tissue Changes

Light and electron microscopic studies involving expanded tissue from both animals and humans have been extensively reported. ${ }^{11-21}$ In general, human and animal soft tissue respond in a similar manner during conventional controlled tissue expansion.

EPIDERMIS. The epidermis in expanded skin thickens in response to expansion. Hyperkeratosis, acanthosis, and increased mitotic activity is noted. ${ }^{11-16}$ Electron microscopy reveals a more undulated basal lamina. Tonofibrils in the basal and prickle (malpighian) cell layers have larger bundles of tonofilaments compared with normal skin. Intercellular spaces in all layers of the epidermis are reduced. ${ }^{13}$ It is hypothesized that the undulation of the basal lamina and decreased intercellular space may be the result of increased epidermal mitotic activity. ${ }^{11}$ The increased epidermal mitotic activity has been demonstrated using autoradiographic techniques. ${ }^{22}$

DERMIs. Significant changes occur in the dermis during controlled tissue expansion. ${ }^{11-15}$ A decrease in the overall thickness of the dermis occurs most rapidly during the 
first several weeks. The papillary and reticular dermis contain large bundles of compacted collagen fibers that show normal cross-banding and periodicity. Thin collagen fibers are also seen. Fibroblasts increase in number, and the rough endoplasmic reticulum of these cells contains large cisternae, indicating increased metabolic activity. ${ }^{11,13}$ Normalization of dermal thickness has been demonstrated 2 years following expansion. ${ }^{15}$

Myofibroblasts are present after several weeks of expansion. Increased metabolic activity in these cells is indicated by the numerous mitochondria and abundant cisternae of rough endoplasmic reticulum. The cytoplasm in myofibroblasts also contains long microfilaments that aggregate in some areas to form "dense bodies." The presence of these myofibroblasts suggests that the dermis may be assuming a contractile function, possibly in response to progressive expansion. Elastic fibers become thick and compact and form clusters. Adnexal structures, such as sweat glands, and hair follicles, are farther apart, but quantitatively and functionally they remain unchanged during tissue expansion. ${ }^{11}$

MUSCLE. A decrease in muscle thickness and mass occurs during expansion but the function of the muscle is maintained. Clinically, there appears to be no functional loss of muscle strength or range-of-motion. Ultrastructurally there is an increased amount of sarcoplasm in relation to myofibrils. The myofibrils are enlarged and the number and size of mitochondria are increased. The sarcomeres are arranged aberrantly and contain irregularly scattered myofilaments. ${ }^{11,13}$

FAT. Adipose tissue is the most affected of all tissues by the expansion process. ${ }^{15,23}$ There is a marked decrease by as much as 30 to $50 \%$ in the number of fat cells and in the thickness of the adipose layer. ${ }^{23}$ Actual fat necrosis does not usually occur during careful tissue expansion. Rarely, the loss of fatty tissue may be permanent as evidenced by biopsy specimens taken years after expansion. ${ }^{11}$

CAPSUlE. A dense fibrous capsule develops around all tissue expanders within a matter of days and completely surrounds the expander. ${ }^{11-13,15,20}$ The capsule is thickest after 2 to 2.5 months of expansion and is composed of elongated fibroblasts and a few myofibroblasts. These cells lie between thick collagen bundles oriented parallel to the surface of the implant (Figure 1). The fibroblasts contain very active rough endoplasmic reticulum with prominent cisternae, and many of these cells have numerous vesicles filled with electron-dense material. Collagen fibers with typical periodicity are found within the cytoplasm of the fibroblasts. The intracellular collagen fibers may be multiple or single. Although most of the fibers are straight, some may be coiled or bent. Intracellular collagen is most often found in specimens taken after the seventh week of expansion. The capsular membrane rapidly thins after removal of the tissue expander, but a readily dissectable plane remains for at least 1 year. Inflammatory reactions and the presence of foreign-body giant-cells within the capsule, epidermis, or dermis may be seen (Figure 2). ${ }^{13,18}$

BLOOD VESSELS. Rapid angiogenesis occurs with the greatest increase in the number of vessels located at the junction between the capsule and the host tissue. Within days after placement of the tissue expander, the number of both arterioles and venules increases, and these vessels appear to communicate with smaller vessles in the upper dermis overlying the tissue expander. The actual increase in vascularity in the expanded tissue helps explain previous studies which demonstrated that, compared with control flaps, the expanded flaps had not only a significantly larger surface area but also an increaed survival length of $117 \%$ over control flaps. ${ }^{18,23-25}$ The explanation for increased vascularity may be related to multiple factors including realignment of vessles, closing of arteriovenous shunts, neovascularization, and the depletion of neurohumoral vasoactive substances. ${ }^{18,20,26}$

BONE. Bone resorption has been rarely described in humans. ${ }^{27-29}$ Tissue expansion causes significant but reversible cranial and long bone changes in neonatal miniature swine ${ }^{30}$ Cranial bone is affected more than long bone. Decreased bone thickness and volume with erosion may occur beneath the expander, but bone density is unchanged. No changes in the inner table of the skull or

Figure 1. Fibrous capsule showing dense fibrous tissue, mild vascular proliferation, and a sprinkling of lymphocytes and eosinophils, (HEE, original magnification $\times 400$ ).

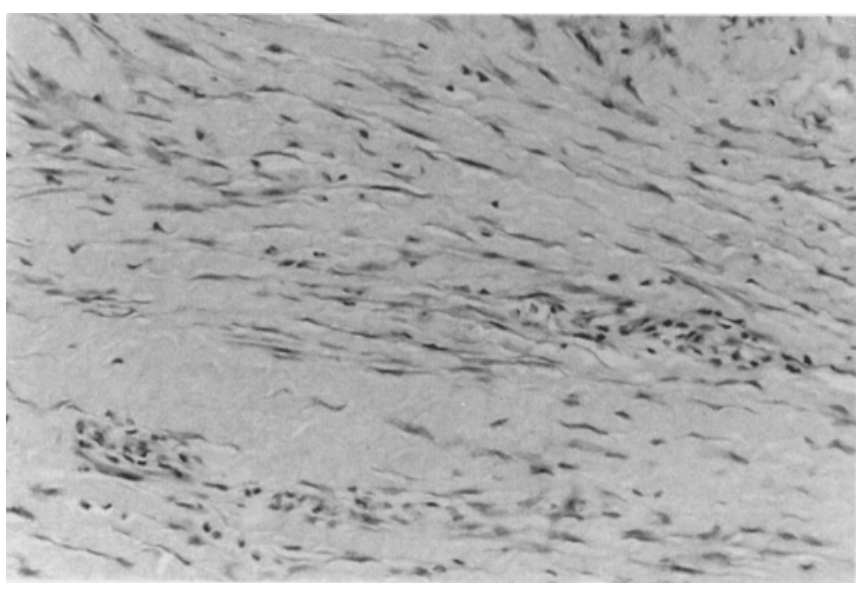




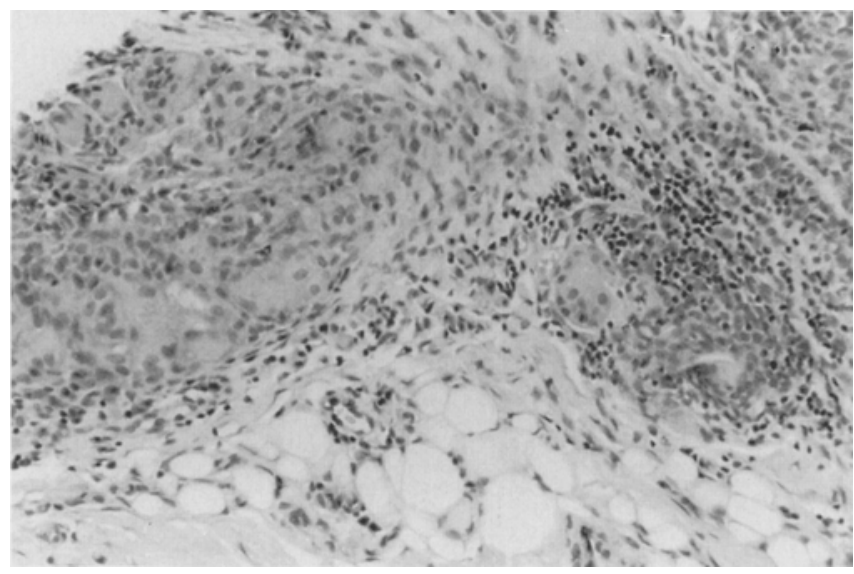

Figure 2. Inflammatory reaction surrounding the fibrous capsule composed of lymphocytes, histiocytes, and foreign body giant cells (HEE, original magnification $\times 400)$.

stigmata of increased intracranial pressure were observed. Increaed osteoclastic bone resorption and inhibition of bone formation occur until the expander is removed. Increased bone thickness, volume, deposition, and lipping occur at the periphery of the expander where a periosteal reaction has been shown. Following removal of expanders, remodeling of bone begins within 5 days and nearly complete healing of cranial defects is demonstrated by 2 months. ${ }^{30}$

\section{Physiology}

The ability of human skin to stretch and increase in surface area to accommodate a slowly enlarging mass beneath it (tissue expansion) is exemplified by abdominal skin during pregnancy, obesity, and Africa customs of lip and neck expansion. Physiologically, expanding tissue will tolerate critically low levels of tissue oxygen tension, approaching $0 \mathrm{mmHg}$. Within 10 to 20 minutes tissue oxygen levels begin to rise and usually return to normal control levels within 48 to 72 hours after inflation of the tissue expander. Full recovery of skin during rest has been repeatedly demonstrated. As the expansion process continues, however, blood flow recovery time is slower ${ }^{31}$ The tissue hypoxia may be a contributing factor to the neovascularization that occurs with tissue expansion.

Clinically, a tissue expander is optimally overinflated to a pressure of about $28 \mathrm{mmHg}$ with each inflation. This usually causes some discomfort, which subsides within 10 to 15 minutes. At this point, the filing solution (usually saline) is withdrawn from the implant until reasonable comfort is obtained. This creates a constant impetus for expansion of the overlying tissue without excessive risk of hypoxic damage. Areas known to be more resis- tant to overinflation include the distal leg, buttocks, midline of the back, and areas previously scarred or irradiated.

The ability of the skin to increase in surface area as a result of conventional controlled tissue expansion can be explained in terms of tissue creep. ${ }^{12,14,22,32}$ Mechanical tissue creep refers to the viscoelastic ability of the skin to acutely stretch in an incremental fashion. This results in an increase in surface area secondary to a loading or stretching force. Biologic tissue creep refers to the actual generation of new tissue secondary to a persistent, chronic stretching force. While mechanical creep plays a role during conventional controlled tissue expansion, compensatory biologic creep is primarily responsible for the generous and significant gain in tissue that is utilized from conventional controlled tissue expansion. Biologic creep is explained partly by increased fibroblast and collagen synthesis, increased myofilaments, increased mitotic activity, and neovascularization. Expanded skin has a significant increase in dermal collagen content because of the biosynthetic activity of dermal fibroblasts. The relative proportions of collagen types I and III, however, are not significantly changed in expanded skin. ${ }^{21}$ The angiogenesis that occurs during slow, controlled expansion provides a highly vascular flap and improves flap viability. The actual amount of increased skin that results from controlled tissue expansion is unknown, but appears to range from 35 to $137 \%{ }^{7,21,33}$ Theoretically, the volume is limited only by the duration and intensity of the expanding force. The phenomenon of stretchback refers to the revision of skin back to its original pre-expansion state. The amount of stretchback is unknown but is suspected to be much less with conventional controlled tissue expansion compared with immediate intraoperative tissue expansion. The amount of tissue gain is dependent not only on the host tissue but also on the shape of the tissue expander. ${ }^{34,35}$ The amount of tissue gain is greater for rectangular and crescentic expanders compared with those with a round base. In general, the surface area of the expander base should be approximately 2.5 times the size of the defect to be closed. ${ }^{18,34}$

\section{Immediate Intraoperative Tissue Expansion}

\section{Ultrastructural and Soft Tissue Changes}

Unlike conventional tissue expansion, very few changes have been noted in rapidly expanded skin., ${ }^{5,7}$ Using the human, porcine, and guinea pig model, no significant changes have been noted in the epidermis, dermis, and fatty layers using light microscopy (hematoxylin-eosin, elastin, and trichrome staining), electron microscopy, and immunofluorescent collagen and elastin staining. ${ }^{5,7}$ 


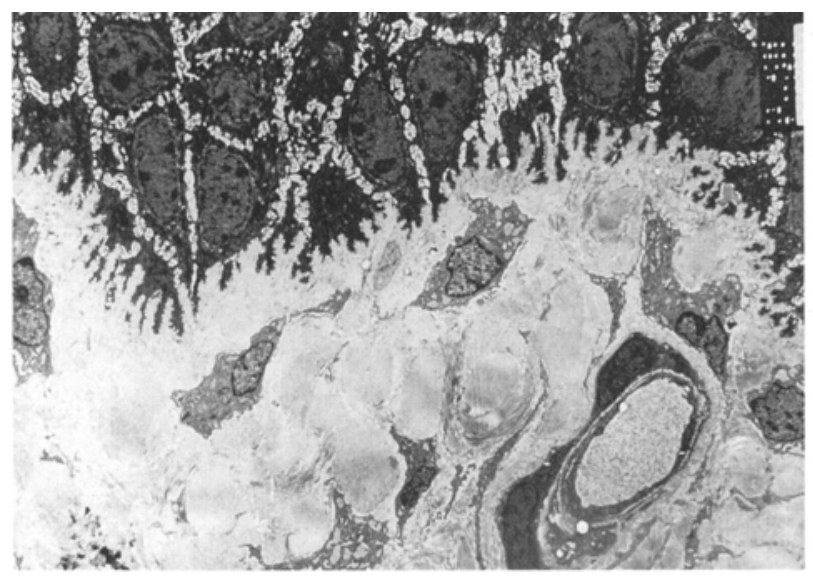

Figure 3. Electron micrograph of non-stretched pig skin demonstrating normal capillary in the papillary dermis.

In the porcine model the only significant finding noted by electron microscopy is the presence of enlarged dermal capillaries (Figures 3,4). This finding correlates with the clinical finding of venous congestion and a blue color seen in rapidly expanded skin noted immediately after expansion. Using laser doppler and fluoroscein studies, blood flow decreases rapidly during expansion but recovers to normal levels within minutes following deflation. ${ }^{5}$

\section{Physiology}

There are many unanswered questions regarding physiologic and biologic changes that occur with immediate tissue expansion and ongoing studies are needed. The actual amount of increased skin resulting from immediate intraoperative expansion is unknown but reports of $31 \%,{ }^{7} 15$ to $20 \%,{ }^{8}$ and 0.5 to $2.5 \mathrm{~cm}^{5,18}$ have been reported depending on the location, host tissue, degree of expansion, and other factors. Immediate intraoperative tissue expansion results in a greater amount of tissue stretch than pulling with skin hooks due to three dimensional stretch compared to two dimensional stretch. ${ }^{7,9}$ The amount of stretchback is presently unknown and requires further study but may be as high as 20 to $30 \%{ }^{18}$

Whereas biologic creep plays a major role in conventional controlled tissue expansion, mechanical creep is the primary mechanism by which the skin is able to acutely stretch and increase in surface area during immediate intraoperative tissue expansion. Mechanical creep is explained by four factors: 1) displacement of fluids and ground substance out of the collagen network leads to relative dehydration of tissue; 2 ) collagen fibers realign in a parallel fashion; 3) elastic fibers microfragment; and 4)

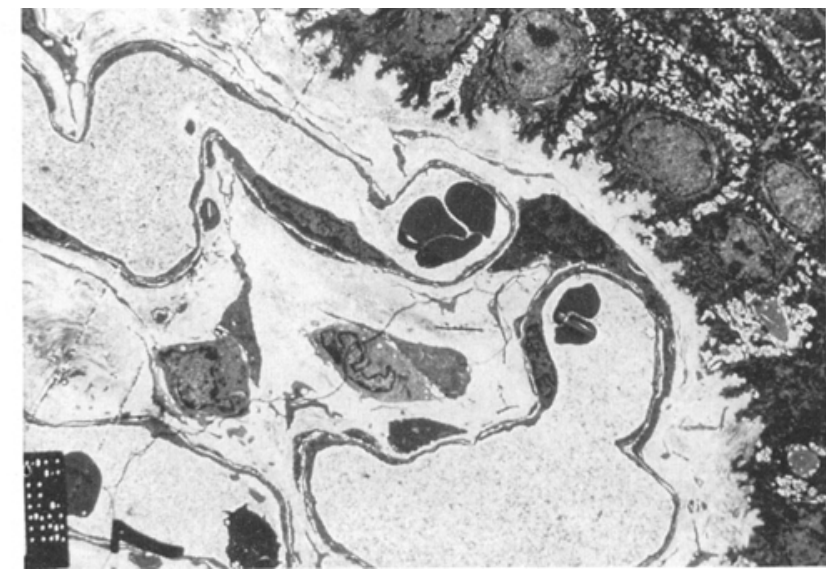

Figure 4. Electron micrograph of stretched pig skin following third immediate expansion cycle. Greatly dilated capillaries are present in the papillary dermis. The basement membrane zone is unchanged.

adjacent tissue migrates into the expanded field as a result of the stretching force. The most effective way to recruit tissue via mechanical creep is by cyclic loading or stretching of the skin. This is the basis for multiple expansion cycles of inflation-deflation used during the immediate expansion technique. ${ }^{18,36,37}$

\section{Conclusion}

Tissue expansion is a remarkable concept based on the skin's natural ability to stretch in response to an underlying force. The initial application of tissue expansion for breast reconstruction has greatly alleviated some of the psychologic and emotional trauma that directly follows a mastectomy. The imaginative minds of many surgeons have broadened and refined the procedure of tissue expansion. Certainly, a thorough understanding of the histology and physiology will play a role in the continued development of this procedure. Many changes occur in the skin and underlying tissues during tissue expansion. Discontinuation of the expansion process usually results in a slow return of these tissues to their pre-expansion state over time. Future study in this area is needed to increase the understanding of immediate intraoperative tissue expansion. As more physicians become aware of the techniques, use, and potential results of tissue expansion, more patients will benefit from its use.

\section{References}

1. Neumann CG. The expansion of an area of skin by progressive distention of the subcutaneous balloon. Plast Reconstr Surg 1957;19:124-30. 
2. Radovan C. Breast reconstruction after mastectomy using the temporary expander. Plast Reconstr Surg 1982;69:195 208.

3. Radovan C. Tissue expansion in soft-tissue reconstruction. Plast Reconstr. Surg 1984;74:482-92.

4. Austad ED, Rose GL. A self-inflating tissue expander. Plast Reconstr Surg 1982;70:588-94.

5. Sasaki GH. Intraoperative sustained limited expansion (ISLE) as an immediate reconstructive technique. Clin Plast Surg 1987;14:563-73.

6. Johnson TM, Brown MD, Sullivan MJ, et al. Immediate intraoperative tissue expansion. J Am Acad Dermatol 1990;22:283-7.

7. Machida BK, Liu-Shindo M, Sasaki GH, et al. Immediate versus chronic tissue expansion. Ann Plast Surg 1991; 26:227-32.

8. Hoffman HT, Baker SR. Nasal reconstruction with the rapidly expanded forehead flap. Laryngoscope 1989;99: 1096-8.

9. Greenbaum SS, Greenbaum $\mathrm{CH}$. Intraoperative tissue expansion using a Foley catheter following excision of a basal cell carcinoma. J Dermatol Surg Oncol 1990;16: $45-8$.

10. Ehlert TK, Thomas JR. Rapid intraoperative tissue expansion for closure of facial defects. Arch Otolaryngol Head Neck Surg 1991;117:1043-9.

11. Argenta LC, Marks MW, Pasyk KA. Advances in tissue expansion. Clin Plast Surg 1985;12:159-71.

12. Austad ED, Pasyk KA, McClatchey KD, et al. Histomorphologic evaluation of guinea pig skin and soft tissue after controlled tissue expansion. Plast Reconstr Surg 1982; 70:704-10.

13. Pasyk KA, Austad ED, McClatchey KD, et al. Electron microscopic evaluation of guinea pig skin and soft tissues expanded with a self-inflating silicone implant. Plast Reconstr Surg 1982;70:37-45.

14. Johnson PE, Kernahan DA, Bauer S. Dermal and epidermal response to soft tissue expansion in the pig. Plast Reconstr Surg 1988;81:390-7.

15. Pasyk KA, Argenta LC, Hassett $C$. Quantitative analysis of the thickness of human skin and subcutaneous tissue following controlled expansion with a silicone implant. Plast Reconstr Surg 1988;81:516-23.

16. Timmenga EJ, Schoorl R, Klopper PJ. Biomechanical and histomorphological changes in expanded rabbit skin. $\mathrm{Br} \mathrm{J}$ Plast Surg 1990;43:101-6.

17. Bartell TH, Mustoe TA. Animal models of human tissue expansion. Plast Reconstr Surg 1989;83:681-6.

18. Baker SR. Fundamentals of expanded tissue. Head Neck 1991;13:327-33.

19. Roenigk RK, Wheeland RG. Tissue expansion in dermatologic surgery. Dermatol Clin 1987;5:429-36.

20. Pasyk KA, Austad ED, Cherry GW. Intracellular collagen fibers in the capsule around silicone expanders in the guinea pig. J Surg Res 1984;36:125-33.

21. Knight KR, McCann JJ, Vanderkolk CA, et al. The redistribution of collagen in expanded pig skin. Br J Plast Surg 1990;43:565-70.

22. Austad ED, Thomas SB, Pasyk K. Tissue expansion: dividend or loan? Plast Reconstr Surg 1986;78:63-7.

23. Leighton WD, Russell RC, Feller AM. Experimental pretransfer expansion of free-flap donor sites: II. physiology, histology, and clinical correlation. Plast Reconstr Surg 1988;82:76-87.

24. Sasaki GH, Pang CY. Pathophysiology of skin flaps raised on expanded pig skin. Plast Reconstr Surg. 1984;74:59-67.

25. Cherry GW, Austad E, Pasyk K, et al. Increased survival and vascularity of random-pattern skin flaps elevated in controlled expanded skin. Plast Reconstr Surg 1983; 72:680-7.

26. Leighton WD, Russell RC, Marcus DE, et al. Experimental pretransfer expansion of free-flap donor sites: I. Flap viability and expansion characteristics. Plast Reconstr Surg 1988;82:69-75.

27. Hemmer KM, Marsh JL, Picker S. Calvarial erosion after scalp expansion. Ann Plast Surg 1987;19:454-9.

28. Antonyshyn O, Gruss JS, Mackinnon SE, et al. Complications of soft tissue expansion. Br J Plast Surg 1988;41: 239-50.

29. Fudem GM, Orgel MG. Full-thickness erosion of the skull secondary to tissue expansion for scalp reconstruction. Plast Reconst Surg 1988;82:368-9.

30. Moelleken BRW, Mathes SJ, Cann CE, et al. Long-term effects of tissue expansion and cranial and skeletal bone development in neonatal miniature swine: Clinical findings and histomorphometric correlates. Plast Reconstr Surg 1990;86:825-34.

31. Canady JW, Squier CA, Kelly KM. Serial measurement of blood flow in expanded tissue by laser Doppler velocimetry. Otolaryngol Head Neck Surg 1990;103:986-90.

32. Gibson T. Discussion. Plast Reconstr Surg 1986;77:320-1.

33. McCann JJ, Mitchell GM, $\mathrm{O}^{\prime}$ Brien B, et al. Comparative viability of expanded and unexpanded axial pattern skin flaps in pigs. Br J Plast Surg 1988;41:294 -7.

34. van Rappard JH, Molenaar J, van Doorn K, et al. Surface area increase in tissue expansion. Plast Reconstr Surg 1988;82:833-9.

35. Brobmann GF, Huber J. Effects of different shaped tissue expanders on transluminal pressure, oxygen tenson, histopathologic changes, and skin expansion in pigs. Plast Reconstr Surg 1985;76:731-6.

36. Gibson T. The physical properties of skin. In: Converse JM, ed. Reconstructive Plastic Surgery, vol 1. Philadelphia: WB Saunders, 1977:70-7.

37. Gibson T, Kenedi RM, Craik JE. The mobile microarchitechure of dermal collagen: a bioengineering study. $\mathrm{Br} J$ Surg $1965 ; 52: 764-9$. 